\title{
CURRÍCULOS ACADÊMICOS E EXTENSÃO UNIVERSITÁRIA: SENTIDOS EM DISPUTA ${ }^{1}$
}

\section{Marcia Serra Ferreira \\ Carmen Teresa Gabriel}

\begin{abstract}
RESUMO
Este artigo tem como objetivo analisar os sentidos de currículo acadêmico e de extensão universitária que têm sido produzidos e que circulam no âmbito acadêmico. Investigando materiais produzidos por diferentes atores sociais que atuam na Universidade Federal do Rio de Janeiro, interessa-nos compreender as lutas hegemônicas responsáveis pelo posicionamento da extensão nos currículos acadêmicos. Dialogando com autores que têm focalizado a universidade (Boaventura de Sousa Santos) e seus currículos (Antonio Flavio Moreira), assim como aqueles que têm problematizado as interfaces entre conhecimento, poder e cultura tais como Alice Casimiro Lopes e Elizabeth Macedo -, sustentamos a idéia de que a extensão, como espaço ambivalente, reproduz e subverte discursos hegemônicos sobre os conhecimentos acadêmicos. A análise realizada permitiu-nos identificar, nos textos investigados, a presença de ambivalências expressas por meio de marcas subversivas e, simultaneamente, de vestígios de outros discursos que participam das lutas hegemônicas pela estabilização de sentidos sobre extensão universitária. Defendemos que a extensão, ao se aproximar da lógica disciplinar, busca se fortalecer no âmbito universitário afastando-se do lugar de subalternidade no qual tem sido historicamente colocada e apostando em um novo campo de possibilidades, ainda que criticando essa mesma lógica por meio da noção (igualmente ambivalente) de 'flexibilização curricular'.
\end{abstract}

\section{PALAVRAS-CHAVE}

Currículo acadêmico; Extensão universitária; Flexibilização curricular

\section{ACADEMIC CURRICULA AND UNIVERSITY EXTENSION: SENSES IN DISPUTE}

\begin{abstract}
This article aims to analyze the senses of academic curriculum and university extension that have been produced and that circulate within academic scope. Investigating materials produced by different social actors who act at the Federal University of Rio de Janeiro, we are interested in understanding the hegemonic struggles responsible for the extension positioning in academic curricula. Dialoguing with authors who have focused on university (Boaventura de Sousa Santos) and its curricula (Antonio Flavio Moreira), as well as those who have problematized the interfaces between knowledge, power and culturesuch as Alice Casimiro Lopes and Elizabeth Macedo -, we defend the idea that the extension, as ambivalent space, reproduces and subverts the hegemonic discourses on academic knowledge. The analysis enabled us to identify, in the investigated texts, the presence of ambivalences expressed through subversive marks and, simultaneously, traces of other speeches that participate on hegemonic struggles for the stabilization of senses on university extension. We defend that the extension, getting closer to disciplinary logic, seeks to strengthen itself in the university scope, deviating from the place of inferiority in which has been historically placed and betting on a new field of possibilities, though criticizing the same logic through the notion (also ambivalent) of 'curricular flexibilization'.
\end{abstract}

\section{KEYWORDS}

Academic curriculum, University extension, Curricular flexibilization.

\footnotetext{
${ }^{1}$ Esse trabalho é fruto da articulação dos projetos "Memória do ensino de Ciências na UFRJ: revitalização do acervo do Projeto Fundão Biologia" (apoio IAC/UFRJ e PIBEX/UFRJ) e "Currículo de Ciências: iniciativas inovadoras nas décadas de 1950/60/70" (apoio CNPq e FAPERJ), ambos coordenados pela primeira autora, com os projetos "Currículos Acadêmicos e estudantes de origem popular: tensões e contestações” (apoio CNPq) e "Currículo de História: investigando sobre saberes aprendidos e construções de sentido", ambos coordenados pela segunda autora. Além disso, dialoga com o projeto de pesquisa "Propostas curriculares e escolas no Brasil e em Portugal", desenvolvido pelas autoras em parceria com universidades brasileiras e portuguesas no âmbito do convênio CAPES/GRICES.
} 


\section{CURRÍCULOS ACADÊMICOS E EXTENSÃO UNIVERSITÁRIA: INVESTIGANDO SENTIDOS}

Este artigo tem como objetivo analisar os sentidos de currículo acadêmico e de extensão universitária que têm sido produzidos, que circulam e que se encontram em disputa no campo universitário. Tomando como referência tanto um texto produzido pela Pró-reitoria de Extensão da Universidade Federal do Rio de Janeiro quanto produções relativas às ações de extensão realizadas por diferentes atores sociais no interior dessa instituição, interessa-nos compreender as lutas hegemônicas responsáveis pelo posicionamento da extensão nos currículos acadêmicos. Nesse movimento, estamos especialmente atentas às estratégias discursivas que têm sido mobilizadas, permitindo leituras heterogêneas que colocam em evidência processos subversivos presentes nas variadas disputas.

A pertinência desse recorte se sustenta em duas ordens de argumentação. A primeira delas diz respeito à escassez de estudos que operam com as contribuições teóricas do campo do Currículo para pensar o fazer curricular na/da cultura universitária. Em artigo recentemente publicado, ao discutir "o processo curricular do ensino superior no contexto atual”, Antonio Flavio Moreira (2005) formula questões que destacam o quanto essa temática ainda está à espera de estudos mais consistentes, instigando outros pesquisadores da área a explorarem algumas das pistas por ele levantadas. Esse texto pode ser visto, portanto, como uma aceitação a essa provocação do autor, particularmente no que se refere às questões por ele elaboradas que articulam diferentes visões de universidade privilegiadas em recentes reformas do ensino superior, com suas implicações nos currículos acadêmicos.

A segunda ordem de argumentação aposta na idéia de que a extensão pode ser percebida como um espaço privilegiado para aprofundar nossas reflexões sobre os currículos acadêmicos na perspectiva anteriormente mencionada. Afinal, em meio a crescentes pressões pela democratização do ensino superior e por reformas curriculares, a universidade pública brasileira é mais uma vez pressionada a se repensar, revendo suas funções relativas à tríade ensino, pesquisa e extensão. Nessa direção, Boaventura de Sousa Santos (2000) destaca que, desde os anos de 1960, aspectos como a criação de novas universidades e a ampliação de vagas naquelas já existentes contribuíram para o acirramento de inúmeras tensões que, ainda hoje, permeiam a cultura universitária, provocadas pelo aumento das funções assumidas por essa instituição no mundo contemporâneo. Para o autor, as reformas universitárias propostas 
nos últimos tempos tendem a produzir mecanismos que, antes de superar contradições, se concentram na gestão e no controle das mesmas. Essa tentativa de gestão e de controle tem sido particularmente problemática em certos domínios, gerando três crises - a "crise de hegemonia”, a “crise de legitimidade” e a “crise institucional” (SANTOS, 2000, p. 190) com as quais a universidade tem que, cotidianamente, lidar.

Neste artigo, exploramos mais detidamente a “crise de hegemonia”, isto é, aquela que coloca em xeque o papel da universidade como locus exclusivo de produção de “conhecimentos exemplares” (SANTOS, 2000, p. 190). Essa crise, além de ser considerada por Boaventura de Sousa Santos como a mais profunda que a universidade vem atravessando nas últimas décadas, nos remete aos debates sobre esses conhecimentos no interior dos currículos acadêmicos sócio-historicamente produzidos no ensino superior. Tal crise pode ser evidenciada, por exemplo, em 'novos' sentidos que vêm sendo elaborados e que ressignificam ‘antigas’ dicotomias envolvendo a questão dos conhecimentos, dentre as quais o autor destaca: alta cultura/cultura popular, educação/trabalho e teoria/prática (SANTOS, 2000).

Como afirmamos anteriormente (GABRIEL; FERREIRA; MONTEIRO, 2008), percebemos a extensão como um espaço acadêmico que tem sido, simultaneamente, valorizado na reflexão sobre o papel político-social e cultural da universidade e desvalorizado em termos de produção do que Boaventura de Sousa Santos (2000, p. 190) denomina de “conhecimentos exemplares”. Entendemos essa ambivalência como possuidora de um potencial subversivo que tem sido utilizado por um conjunto de atores sociais envolvidos com a extensão universitária, explicitando as diferentes estratégias produzidas para enfrentar as tensões relativas à hierarquização dos conhecimentos científicos frente às exigências sóciopolíticas da democratização. Tais estratégias, produzidas em meio às crises identificadas por Santos (2000), explicitam movimentos de mudanças nas políticas de currículo no âmbito universitário no interior de quadros aparentemente estáveis.

Retomando aqui a idéia da extensão universitária como um espaço ambivalente e subversivo produtor de políticas de currículo, iniciamos nossa argumentação explicitando as vinculações teóricas no campo do Currículo que nos distanciam de perspectivas de análise dicotômicas e que operam, predominantemente, com a linguagem da denúncia. Em seguida, apresentamos nossa análise relativa aos documentos sobre extensão produzidos no âmbito da Universidade Federal do Rio de Janeiro, buscando evidenciar as recontextualizações e as 
hibridizações dos sentidos de currículo acadêmico e de extensão universitária que têm sido negociados e disputados.

\section{CURRÍCULOS ACADÊMICOS E EXTENSÃO UNIVERSITÁRIA: VINCULAÇÕES TEÓRICAS}

Buscando explicitar as vinculações teóricas que nos permitem sustentar a idéia de que a extensão, como espaço ambivalente, reproduz e subverte os discursos hegemônicos sobre os conhecimentos acadêmicos, investimos no diálogo com curriculistas que têm problematizado as interfaces entre conhecimento, poder e cultura. Dentre esses autores, privilegiamos aqueles que nos permitem significar currículo tal como o faz Elizabeth Macedo (2003/2004, p. 25), isto é, como “um híbrido em que a diferença é negociada num espaçotempo ambivalente em que os discursos homogêneos convivem com os saberes locais”, na medida em que seus trabalhos nos fornecem outras pistas para pensar a politização dos debates em torno das questões curriculares. Nessa perspectiva, estudos que entendem as políticas de currículo como políticas culturais - tais como os de Stephen Ball (1998 e 2001), Rosane Dias \& Alice Casimiro Lopes (2003), Rita Frangela (2007), Carmen Teresa Gabriel (2008a e 2008b), Carmen Teresa Gabriel, Marcia Serra Ferreira \& Ana Maria Monteiro (2008), Alice Casimiro Lopes (2005 e 2006), Elizabeth Macedo (2003/2004, 2006a, 2006b e 2006c), Ana Angelita Rocha (2008) e Letícia Terreri (2008) - abrem caminhos para a compreensão da extensão universitária como espaço-tempo produtor de sentidos híbridos sobre currículo.

Ao optarmos, ao lado dos autores supramencionados, por definir cultura como “processos sociais de significação” (GARCÍA CANCLINI, 2005, p. 41), entendemos as políticas de currículo como algo que se sucede no conflito, como choque de significados nas fronteiras, configurando "modos específicos pelos quais os atores se enfrentam, se aliam ou negociam” (GRIMSON, 2003, p. $71^{2}$ apud GARCÍA CANCLINI, 2005, p. 48). Como afirma Nestor García Canclini (2005, p. 128), estudar a cultura requer, então, a conversão de cada pesquisador em uma espécie de “especialista das interseções”.

No campo do Currículo, Elizabeth Macedo (2006c) sugere, por exemplo, que um dos maiores desafios da atualidade é pensar nas possibilidades ou modalidades dessa interação, diálogo e/ou tradução entre “culturas” em termos de convivência, "tendo em vista

\footnotetext{
${ }^{2}$ GRIMSON, A. Tram(p)as de La comunicación y la cultura. Buenos Aires: Universidad de La Plata, 2003.
} 
as relações de poder que permeiam sua própria existência”. Sem pretender operar com as noções de cultura e de conhecimento como sinônimas, reconhecemos que tais reflexões possuem implicações diretas nos currículos acadêmicos. Afinal, os processos de produção e de circulação de sentidos sobre currículo ocorrem em um campo de disputas em torno de sentidos sobre conhecimentos socialmente legitimados no âmbito universitário.

Além disso, entendemos que a nossa opção por participar desse debate apostando no potencial analítico das políticas de currículo como políticas culturais abre caminhos para repensar as relações de poder, de modo a superar visões dicotômicas e hierarquizadas que ora percebem essas políticas apenas produzidas pelo Estado, ora entendem as instituições de ensino como completamente autônomas nesses processos. Trabalhamos, portanto, com a idéia de uma circularidade das políticas que são produzidas nas várias instâncias e não apenas no plano estatal (BALL; BOWE, 1992; BALL, 1998 e 2001; LOPES, 2005 e 2006), percebendo a interpenetração de estratégias desenvolvidas nas diferentes escalas nas quais se produzem os currículos acadêmicos.

Isso significa operar com as noções de circularidade e de subversão que, ao se associarem ao conceito de hibridismo, incorporam uma crítica radical à noção de hierarquias. Essa associação amplia o potencial investigativo de ambas as noções, oferecendo pistas para pensar as políticas de currículo como políticas culturais que, em uma perspectiva antihegemônica, implicam no favorecimento da heterogeneidade de discursos e de sujeitos (LOPES, 2005). Compreendemos que essas categorias de análise podem trazer novos olhares para uma reflexão sobre a democratização da universidade pública brasileira que incorpore a questão da legitimidade das formas de conhecimento no âmbito acadêmico.

Nessa perspectiva, ao refletirmos sobre as reformas do ensino superior brasileiras, estamos nos referido a um conjunto de textos que são permanentemente produzidos, recontextualizados e hibridizados em diferentes contextos: o "contexto de influência”, onde ocorrem disputas dos diversos grupos que atuam em espaços como governos, partidos políticos e agências multilaterais, produzindo sentidos sobre as finalidades sociais da educação e sobre o que significa ser educado; o “contexto de produção dos textos das políticas”, no qual atua o poder central propriamente dito, em estreita associação com o contexto anterior, produzindo e disseminando discursos das definições políticas; e o "contexto da prática”, onde esses discursos são mais uma vez produzidos, recontextualizados e hibridizados em instituições como universidades e escolas (BALL; BOWE, 1992). 
Entendemos, assim, os documentos sobre extensão elaborados no âmbito da Universidade Federal do Rio de Janeiro como espaços discursivos que, embora produzidos no contexto da prática, fazem circular sentidos híbridos de currículo que foram elaborados também nos outros contextos. Desse modo, investigar a instituição já mencionada significa acessar tanto uma produção de sentidos 'localizada', relacionada às diversas disputas entre os atores e grupos sociais que, historicamente, atuam nesse contexto, quanto os sentidos elaborados, recontextualizados e hibridizados nos contextos de influência e de produção que participam do ciclo produtor de políticas para os currículos acadêmicos.

Compreender essa produção de sentidos sobre currículo na universidade pública brasileira, focalizando, especificamente, as ações de extensão, implica participarmos das lutas hegemônicas acerca de quais conhecimentos 'deveriam' estar legitimados nos cursos de formação universitária. Afinal, embora nessas lutas estejam presentes discursos que investem na noção de que a instituição deve atuar, de modo equilibrado, em meio à tríade ensino, pesquisa e extensão, esses não têm sido hegemônicos na produção de sentidos sobre os currículos acadêmicos. Com efeito, os discursos sobre esses currículos vêm sendo historicamente hibridizados com discursos hegemônicos sobre conhecimento que privilegiam os “conhecimentos exemplares”, embora em disputa com os saberes voltados para a formação profissional (SANTOS, 2000, p. 190).

Investigar a extensão em tempos de “crise de hegemonia” (SANTOS, 2000, p. 190) significa, portanto, não apenas evidenciar as estratégias discursivas contra-hegemônicas que permitem ressignificar esses currículos, como dar visibilidade às ações que contribuem para a construção de uma agenda política de extensão com maior potencial subversivo. Afinal, como aponta Boaventura de Sousa Santos (2000), essa crise, ao desestabilizar os discursos hegemônicos sobre conhecimento, cria estratégias de controle e, simultaneamente, de subversão da mesma. Nesse trabalho, a extensão é percebida como um entre-lugar produtor de ambas as estratégias, uma vez que nele se luta por sua aceitação formal nos currículos acadêmicos, apostando tanto na negociação com o já estabelecido quanto na produção de 'novos' sentidos subversivos de conhecimento e de currículo. Buscando desenvolver esse argumento, na próxima seção tecemos um conjunto de notas a partir dos materiais empíricos selecionados. 


\section{CURRÍCULOS ACADÊMICOS E EXTENSÃO UNIVERSITÁRIA: NOTAS A PARTIR DA EMPIRIA}

Nossa análise sobre os sentidos de currículos produzidos, recontextualizados e hibridizados nas ações de extensão tem como base empírica os seguintes documentos, elaborados no âmbito da Universidade Federal do Rio de Janeiro: o texto oficial intitulado “Proposta para a Institucionalização da Extensão da UFRJ”, elaborado em 2006 pela PróReitoria de Extensão da instituição ${ }^{3}$, e resumos dos trabalhos de extensão apresentados, em 2007, no “4 Congresso de Extensão da UFRJ”, e publicados nos anais do evento ${ }^{4}$.

A escolha do primeiro documento justifica-se pela importância que o mesmo assume no processo de institucionalização da extensão nesta universidade - aspecto sugerido no seu próprio nome -, em um momento de discussão de mudanças internas em meio a um movimento mais amplo de reformas do Ensino Superior no país. Trata-se de um plano de ação da administração central para os anos de 2006/2007, mas que, ainda hoje, serve como texto norteador da produção de políticas de extensão na instituição. Estruturado em torno de onze diretrizes que se desdobram em metas e ações, este documento permite leituras heterogêneas dos sentidos de currículo acadêmico e de extensão universitária que se pretendem hegemônicos.

Já os resumos publicados nos anais do " $4^{\circ}$ Congresso de Extensão da UFRJ" foram selecionados a partir dos trabalhos inscritos pelos próprios autores na área temática “Educação”, uma vez que esta foi percebida por nós como reunindo, senão exclusivamente, prioritariamente, as produções que articulavam extensão e formação profissional. Assim, em um universo de cento e quarenta e quatro resumos da referida área temática, selecionamos quarenta e dois cuja escrita explicitava essa articulação. O critério escolhido mostrou-se fecundo para explorar os sentidos de currículo acadêmico e de extensão universitária hibridizados com os discursos sobre conhecimento produzidos nas diversas unidades acadêmicas da Universidade Federal do Rio de Janeiro.

Além disso, defendemos que a escolha desse critério nos permitiu operar empiricamente com um universo de trabalhos que carregam, potencialmente, sentidos

\footnotetext{
3 UFRJ. Propostas para a institucionalização da extensão na UFRJ. Rio de Janeiro: Pró-Reitoria de Extensão/PR5, 2006.

${ }^{4}$ UFRJ. Anais do $4{ }^{\circ}$ Congresso de Extensão da UFRJ. Rio de Janeiro: Pró-Reitoria de Extensão/PR5, 2007.
} 
subversivos de extensão, uma vez que os textos selecionados investem em discursos que a significam como ação voltada para o interior da universidade. Isso significa dizer que esses textos, ao invés de apenas reforçarem idéias sobre extensão como um movimento 'para fora' do mundo acadêmico, como ação por meio da qual o conhecimento científico é disponibilizado e/ou ‘doado’ à comunidade, operam, de algum modo, também com a noção de que ela é um movimento 'para dentro', na medida em que estendem o campo de formação profissional dos graduandos de diferentes cursos.

Importa sublinhar que esse critério de seleção, o qual nos permitiu identificar a presença de marcas subversivas em análise preliminar do material empírico, não nos impediu de perceber, em uma segunda leitura, vestígios de outros discursos que participam das lutas hegemônicas pela estabilização de sentidos sobre extensão universitária. Com efeito, sentidos de extensão como, por exemplo, os de “estender seus canais de difusão [da produção acadêmica nacional] para a sociedade" ${ }^{5}$, que reforçam a idéia de extensão 'para fora' dos muros da academia, aparecem hibridizados em um mesmo fragmento discursivo com os sentidos potencialmente subversivos.

Essas percepções da extensão universitária que mesclam, simultaneamente, idéias de divulgação dos “conhecimentos exemplares” (SANTOS, 2000, p. 190) produzidos no âmbito acadêmico com noções 'internas’ voltadas para a própria ampliação da formação inicial dos graduandos, são aqui analisadas como resultantes do papel estratégico ocupado pela mesma na gestão e no controle da "crise de hegemonia" definida por Boaventura de Sousa Santos (2000, p. 190). Afinal, embora a extensão permaneça ocupando os espaços que, historicamente, vieram sendo destinados a ela, luta por sua aceitação formal nos currículos acadêmicos produzindo sentidos que apostam na sua "integração com as atividades de ensino

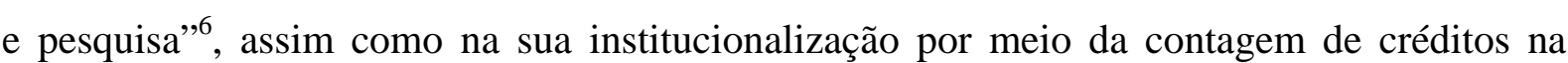
formação universitária. Observe como essa questão aparece claramente explicitada, por exemplo, na segunda diretriz do documento da Universidade Federal do Rio de Janeiro, bem como em uma de suas metas e na ação dela decorrente:

\footnotetext{
${ }^{5}$ SILVA, L. R. et al. Os eventos de extensão promovidos pelo Programa de Estudos Medievais da UFRJ: balanço do ano 2007. In: UFRJ. Anais do $4^{\circ}$ Congresso de Extensão da UFRJ. Rio de Janeiro: Pró-Reitoria de Extensão/PR5, 2007, p. 149.

${ }^{6}$ UFRJ. Propostas para a institucionalização da extensão na UFRJ. Rio de Janeiro: Pró-Reitoria de Extensão/PR5, 2006.
} 
Diretriz 2 - Institucionalização da estrutura e da gestão acadêmica da Extensão em todos os âmbitos da Universidade possibilitando a integração com as atividades de ensino e pesquisa bem como a qualificação das atividades de extensão por parte dos profissionais envolvidos. Meta 2.1 - Valorização da Extensão. Ação - Promover a flexibilização curricular na UFRJ incorporando as atividades de extensão desenvolvidas pelos estudantes como créditos de disciplinas (grifos nossos). ${ }^{7}$

No trecho anterior, percebemos que essa busca pela "institucionalização" da extensão na Universidade Federal do Rio de Janeiro, como estratégia para a sua "valorização" no âmbito universitário, se faz por uma aproximação ou inserção da mesma na lógica hegemônica da disciplinarização curricular. Assim, ao indicar como uma ação relacionada à meta 2.1 a promoção da “flexibilização curricular”, o documento também reafirma, ainda que de modo implícito, uma crítica já recorrente quando se fala tanto em currículos acadêmicos quanto em currículos escolares, a qual aposta em uma suposta rigidez da estrutura disciplinar. Interpretamos, portanto, que o mesmo movimento que problematiza essa lógica disciplinar, propondo uma "flexibilização curricular", a reforça quando negocia com o instituído e indica que as atividades de extensão devem ser formalmente reconhecidas por meio da inclusão de “créditos de disciplinas” em ações curriculares.

Esse mesmo tipo de ambivalência - isto é, aquela que aposta em uma aproximação e, ao mesmo tempo, em uma crítica à lógica disciplinar - é reforçada no texto introdutório do mesmo documento produzido pela Pró-reitoria de Extensão da universidade, ao explicitar que a incorporação das atividades de extensão no currículo disciplinar deve ocorrer em um processo de “flexibilização curricular”:

\begin{abstract}
Além das 500 bolsas, o PIBEX já consagra os novos princípios que devem nortear as atividades de extensão na nossa universidade, adotados como critérios de seleção em ambos os editais: a indissociabilidade extensão-ensino-pesquisa; a valorização da extensão como atividade acadêmica, promovendo a incorporação das atividades desenvolvidas pelos alunos como créditos de disciplinas (em um processo de implantação da Flexibilização Curricular na UFRJ); a integração de diversos projetos isolados em Programas; o caráter inter e transdisciplinar de suas atividades; o vínculo e o compromisso com populações-alvo bem como a definição de territórios prioritários; entre outros (grifos nossos). ${ }^{8}$
\end{abstract}

\footnotetext{
7 UFRJ. Propostas para a institucionalização da extensão na UFRJ. Rio de Janeiro: Pró-Reitoria de Extensão/PR5, 2006.

${ }^{8}$ UFRJ. Propostas para a institucionalização da extensão da UFRJ. Rio de Janeiro: Pró-Reitoria de Extensão/PR5, 2006, p. 3-4.
} 
Importa sublinhar que, no quadro teórico aqui privilegiado, não entendemos a ambivalência como fragilidade ou como inconsistência teórica e/ou política. Diferentemente, buscamos compreendê-la de forma positiva, como condição mesma do social, como característica do campo da discursividade no qual ocorrem lutas hegemônicas pelas fixações dos sentidos que se pretendem unívocos. Afinal, o mesmo processo de disciplinarização que restringe e que controla os currículos acadêmicos pode ser percebido como institucionalizador de práticas curriculares que abrem novas possibilidades de ação (GOODSON, 1995 e 1997; FERREIRA, 2005 e 2007). Assim, nas disputas em torno do significante extensão, são produzidos sentidos que, ao aproximarem suas atividades da lógica disciplinar, buscam fortalecê-la no âmbito universitário afastando-a do lugar de subalternidade no qual tem sido historicamente colocada. Tais sentidos apostam em um novo campo de possibilidades, ainda que criticando essa mesma lógica por meio da noção (igualmente ambivalente) de “flexibilização curricular”.

Essa mesma argumentação pode ser sustentada por meio de nossa análise dos resumos publicados nos anais do “ $4^{\circ}$ Congresso de Extensão da UFRJ”. Com efeito, entendemos que, nesses materiais, a ambivalência de discursos sobre extensão universitária se manifesta por diferentes marcas textuais, as quais indicam, como dissemos anteriormente, as disputas em torno da estabilização de certos sentidos que se pretendem hegemônicos. Como já afirmado, no presente estudo focalizamos nossos olhares nas relações estabelecidas entre extensão e conhecimento nos discursos produzidos, recontextualizados e hibridizados nos currículos acadêmicos.

Nossa análise dos resumos permite-nos destacar que a extensão tem sido significada como um lugar sem conhecimento próprio, isto é, não produtor de conhecimentos específicos. O entendimento da extensão como esse 'não-lugar' epistemológico mobiliza e reatualiza diferentes discursos sobre conhecimento no enfrentamento da "crise de hegemonia”, fazendo com que, nas lutas em torno desse significante, sejam disputados outros espaços curriculares ainda não ocupados hegemonicamente pelos "conhecimentos exemplares” (SANTOS, 2000, p. 190). Essa estratégia passa pela ocupação desses outros espaços curriculares voltados, predominantemente, para a formação profissional, buscando investir em 'novos' sentidos para significantes como 'prática', 'contato com a realidade' e ‘comprometimento político’. 
No que se refere aos sentidos de 'prática’ voltados para a formação profissional, os resumos analisados investem em uma noção de 'novidade’ apostando, por exemplo, “na construção de um novo caminho de intervenções educacionais e que promovem a reflexão sobre a própria prática docente” ${ }^{\text {. }}$. Desdobramentos dessa noção podem ser percebidos em trabalhos que valorizam entendimentos de prática voltados para 'metodologias de ensino inovadoras’, afirmando ser um dos projetos, por exemplo, “um rico laboratório de formação dos futuros profissionais do ensino, desafiando-os a utilizar métodos menos ortodoxos e mais cativantes”10, ou oferecendo "aos atuais e futuros professores instrumentos para tornar a Matemática útil e prazerosa, contribuindo, também, para diminuir o analfabetismo funcional dos alunos”11. Além desses sentidos de 'prática' que promovem certas metodologias de ensino percebidas como 'inovadoras', aparecem noções voltadas para uma visão humanizadora da mesma. Afinal, para os autores de um dos resumos analisados, a "formação acadêmica regular não oferece a oportunidade de lidar com pessoas e tecnologia ao mesmo tempo, o que não é fácil, pois é um ambiente onde sempre as partes andam em sincronia, e devemos perceber até onde é benéfica a atuação da tecnologia»12.

Já os resumos que apostam no 'contato com a realidade' investem em sentidos que, por exemplo, contribuem para a formação profissional ampliando o universo cultural dos estudantes de graduação "por meio de apresentações [musicais] àquela comunidade e para fora dela e incentiva a especialização de estudantes de Graduação em Música da UFRJ em repertório da MPB, com a confecção de novos arranjos”"13. Outros trabalhos produzem sentidos que explicitam o quanto a extensão universitária permite um 'contato com a

\footnotetext{
${ }^{9}$ CRUZ, T. A. F. O professor-estagiário em cena: a formação de professores no projeto Pré-Vestibular de Nova Iguaçu. In: UFRJ. Anais do $4^{\circ}$ Congresso de Extensão da UFRJ. Rio de Janeiro: Pró-Reitoria de Extensão/PR5, 2007, p. 112.

${ }^{10}$ SILVA, A. H. M. et al. Pré-vestibular Samora Machel: Atividades sócio-culturais como eixo motivador para o ensino. In: UFRJ. Anais do $4^{\circ}$ Congresso de Extensão da UFRJ. Rio de Janeiro: Pró-Reitoria de Extensão/PR5, 2007, p. 117.

${ }^{11}$ BIGHI, C. C.; PORTO, V. M. F. \& LEITE LOPES, M. L. M. Grafos: jogos e aplicações multidisciplinares. In: UFRJ. Anais do $4^{\circ}$ Congresso de Extensão da UFRJ. Rio de Janeiro: Pró-Reitoria de Extensão/PR5, 2007, p. 127.

${ }^{12}$ NUNES, D. S. \& DIAS, D. S. Sistema de gestão de aprendizagem em trabalho colaborativo - MOODLE. In: UFRJ. Anais do $4^{\circ}$ Congresso de Extensão da UFRJ. Rio de Janeiro: Pró-Reitoria de Extensão/PR5, 2007, p. 153.

${ }^{13}$ SENA, M. A. S. R. Toque... E se toque! - A construção da identidade dos jovens de comunidades populares a partir do aprendizado em música. In: UFRJ. Anais do $4^{\circ}$ Congresso de Extensão da UFRJ. Rio de Janeiro: PróReitoria de Extensão/PR5, 2007, p. 131.
} 
realidade’ que “é diferente, tanto pela extensão do tempo, como pela perspectiva profissional com a qual é realizada"14. Afinal,

Do ponto de vista do processo de aprendizagem, pode ser observado que os alunos, em geral, sofrem uma espécie de desencanto quando, no trabalho cotidiano com as famílias, observam que elas não são muito diferentes, e que estão aí em busca de terra, ou seja, querem ser proprietários privados de uma pequena parcela de terra. Do lado do movimento social, esta é uma experiência nova, já que habitualmente a prática do movimento com estudantes e professores das universidades consiste ora na realização de pesquisa (na que o movimento é tratado como 'objeto' reificado da pesquisa), ora na realização de estágio 'vivência' onde os alunos permanecem um determinado período de tempo (uma ou duas semanas) com as famílias de uma área. ${ }^{15}$

Em termos de um investimento em sentidos de uma extensão comprometida politicamente, percebemos a presença, nos resumos analisados, de discursos recorrentes que, ao se hibridizarem com os discursos sobre formação profissional, atribuem à extensão a responsabilidade de "contribuir para a formação de graduandos comprometidos com o projeto, e na transformação da realidade da comunidade escolar - professores, alunos e funcionários”16. Trata-se, nesses discursos, de reafirmar um significado de extensão associado ao lugar da crítica política, do engajamento e da reflexão sobre o papel social da universidade, permitindo que os graduandos possam desenvolver "uma percepção única relativa aos conflitos da comunidade, propiciando a construção empírica do processo pedagógico e a fomentação de um senso crítico sobre a aplicabilidade da Educação Ambiental que só pode ser obtida através da prática”"17.

\section{CURRÍCULOS ACADÊMICOS E EXTENSÃO UNIVERSITÁRIA: SENTIDOS EM DISPUTA}

O exercício de análise aqui realizado, ainda que preliminar, permite-nos compreender os mecanismos discursivos mobilizados para significar a extensão, os quais tem viabilizado a sua implementação e garantido a sua continuidade na Universidade Federal do

\footnotetext{
${ }^{14}$ DAL MORO, M. \& ACOSTA, L. Serviço social e movimento dos trabalhadores rurais sem terra (MST): uma experiência de estágio e extensão. In: UFRJ. Anais do $4^{\circ}$ Congresso de Extensão da UFRJ. Rio de Janeiro: PróReitoria de Extensão/PR5, 2007, p. 189.

${ }^{15}$ DAL MORO, M. \& ACOSTA, L. Serviço social e movimento dos trabalhadores rurais sem terra (MST): uma experiência de estágio e extensão. In: UFRJ. Anais do $4^{\circ}$ Congresso de Extensão da UFRJ. Rio de Janeiro: PróReitoria de Extensão/PR5, 2007, p. 189.

${ }^{16}$ LEVIS, C. et al. Inserção da Educação Ambiental na Escola Municipal Tenente Antônio João. In: UFRJ. Anais do $4^{\circ}$ Congresso de Extensão da UFRJ. Rio de Janeiro: Pró-Reitoria de Extensão/PR5, 2007, p. 215.

${ }^{17}$ LEVIS, C. et al. Inserção da Educação Ambiental na Escola Municipal Tenente Antônio João. In: UFRJ. Anais do $4^{\circ}$ Congresso de Extensão da UFRJ. Rio de Janeiro: Pró-Reitoria de Extensão/PR5, 2007, p. 215.
} 
Rio de Janeiro sem os mesmos limites impostos pelos processos de institucionalização de maior prestígio no espaço acadêmico. Ao significar a extensão como um 'não-lugar' epistemológico, esses textos produzem sentidos que reforçam discursos naturalizados sobre o que Boaventura de Sousa Santos denomina de “conhecimentos exemplares” (SANTOS, 2000, p. 190). Entendemos que, ao abrirem mão das disputas em torno dos sentidos atribuídos a esses conhecimentos de maior prestígio nos currículos acadêmicos, os produtores da extensão no âmbito universitário a fragilizam e, simultaneamente, a fortalecem, investindo em uma “flexibilização curricular” que passa pelo aspecto que tem sido significado como 'frágil' na formação profissional dos diversos cursos de graduação: o seu caráter prático.

Essa estratégia tem permitido a institucionalização dessas ações de extensão na instituição investigada, o que tem significado torná-las tanto visíveis e legítimas quanto objetos de maior controle da universidade. Tal controle, no entanto, por estar localizado em um espaço sócio-historicamente percebido como de menor prestígio frente à pesquisa e ao ensino - ações relacionadas, respectivamente, à produção e disseminação dos já mencionados “conhecimentos exemplares” (SANTOS, 2000, p. 190) -, tende a estar submetido a regras mais frágeis e flexíveis, permitindo a produção de novos discursos híbridos e ambivalentes acerca dos currículos acadêmicos.

Compreendemos, portanto, que institucionalizar é controlar, mas, igualmente, é fortalecer e permitir avanços. No caso específico das lutas que têm sido travadas no âmbito da Universidade Federal do Rio de Janeiro, os processos de institucionalização têm produzido sentidos sobre a extensão universitária que a colocam ocupando, prioritariamente, nos currículos acadêmicos, o lugar da prática profissional. Assim, buscando ocupar e flexibilizar um espaço curricular historicamente disciplinar, esses trabalhos investem na produção de sentidos que também questionam esses currículos. Apostando na positividade dessa ambivalência, percebemos a extensão universitária como potencialmente subversiva, recolocando-nos questões que, ainda hoje, estão fomentando nossas reflexões e disputas na universidade. Afinal, como participar dos currículos acadêmicos sem perder esse potencial subversivo? Como flexibilizar os currículos acadêmicos sócio-historicamente posicionados apoiando e, simultaneamente, questionando a lógica disciplinar? Como produzir sentidos de extensão universitária que subvertam esse 'não-lugar' epistemológico da extensão universitária? 


\section{REFERÊNCIAS}

BALL, S. J.; BOWE, R. The policy processes and the processes of policy. In: BOWE, R.; BALL, S. J.; GOLD, A. (Orgs.) Reforming education and changing schools: case studies in policy sociology. London/New York: Routledge, p. 6-23, 1992.

Big policies/small world: an introduction to international perspectives in education policy. Comparative Education, v. 34, n. 2, p. 119-129, 1998.

Diretrizes políticas globais e relações políticas locais em educação. Currículo sem Fronteiras, v. 1, n. 2, p. 99-116, 2001.

DIAS, R. E. \& LOPES, A. C. Competências na formação de professores no Brasil; o que (não) há de novo. Educação e Sociedade, v. 24, n. 85, p.1155-1177, 2003.

FERREIRA, M. S. A história da disciplina escolar Ciências no Colégio Pedro II (19601980). 209 fl. Tese (Doutorado em Educação) - Faculdade de Educação da Universidade Federal do Rio de Janeiro, Rio de Janeiro. 2005.

. Investigando os rumos da disciplina escolar Ciências no Colégio Pedro II (19601970). Educação em Revista, n. 45, p. 127-144, 2007.

FRANGELLA, R. C. Profissionalidade - currículo da formação de professores - Educação Infantil: identidade sólida em tempos incertos? In: Anais do VIII Encontro de Pesquisa em Educação da Região Sudeste. Vitória: ANPEd, PPGE/UFES, Edufórum, p. 1-14, 2007.

GABRIEL, C. T. E se o currículo fosse multiculturalmente orientado? In: Anais do XIV Encontro Nacional de Didática e Prática de Ensino. Porto Alegre: PUCRS e UNISINOS, 2008a.

Conhecimento escolar, cultura e poder: desafios para o campo do Currículo em “tempos pós”. In: MOREIRA, A. F. \& CANDAU, V. M. (Orgs.) Multiculturalismo: diferenças culturais e práticas pedagógicas. Petrópolis: Vozes, p. 212-245, 2008b.

.; FERREIRA, M. S.; MONTEIRO, A. M. Democratização da universidade pública no Brasil: circularidades e subversões nas políticas de currículo. In: LOPES, A. C. et al. (Orgs.) Políticas educativas e dinâmicas curriculares no Brasil e em Portugal. Rio de Janeiro: DP et Alii, p. 251-266, 2008.

GARCÍA CANCLINI, N. Culturas híbridas: estratégias para entrar e sair da modernidade. São Paulo: EDUSP, 1997.

GOODSON, I. F. Currículo: teoria e história. Petrópolis: Vozes, 1995.

A construção social do currículo. Lisboa: Educa, 1997.

LOPES, A. C. Política de currículo: recontextualização e hibridismo. Currículo sem Fronteiras, v. 5, n. 2, p. 50-64, 2005. 
2006.

Discursos nas políticas de currículo. Currículo sem Fronteiras, v. 6, n. 2, p. 33-52,

MACEDO, E. Currículo e hibridismo: para politizar o currículo como cultura. Educação em Foco, v. 8, n. 1 e 2, p. 13-30, 2003/2004.

- Currículo como espaço-tempo de fronteira cultural. Revista Brasileira de Educação, v. 11, n. 32, p. 285-296, 2006a.

2006b.

Currículo: política, cultura e poder. Currículo sem Fronteiras, v. 6, n. 2, p. 98-113,

Por uma política da diferença: o que está em pauta em nossas políticas educacionais?

Cadernos de Pesquisa, v. 36, n. 128, p. 327-356, 2006c.

MOREIRA, A. F. O processo curricular do ensino superior no contexto atual. In: PASSOS, I. P. A.; NAVES, M. L. P. (Orgs.) Currículo e avaliação na Educação Superior. Araraquara: Junqueira \& Marin, p. 1-24, 2005.

ROCHA, A. A. C. N. No entrecruzamento de políticas de currículo e de formação docente: uma análise do manual do professor do livro didático de geografia. 2008. 175 fl. Dissertação (Mestrado) - Faculdade de Educação da Universidade Federal do Rio de Janeiro, Rio de Janeiro, 2008.

SANTOS, B. S. Da idéia de universidade a universidade de idéias. In: Pela mão de Alice: o social e o político na pós-modernidade. 7ª ed. São Paulo: Cortez, p. 187-233, 2000.

TERRERI, L. Políticas curriculares para a formação de professores em Ciências Biológicas: investigando sentidos de prática. 2008. Dissertação (Mestrado). Faculdade de Educação da Universidade Federal do Rio de Janeiro, Rio de Janeiro, 2008. 
MARCIA SERRA FERREIRA

Doutora em Educação pela Universidade Federal do Rio de Janeiro. Professora de Didática e de Prática de Ensino do curso de Licenciatura em

Ciências Biológicas e do Programa de Pós-graduação em Educação da mesma instituição. Vice-diretora da Faculdade de Educação (FE/UFRJ) e vicepresidente da Associação Brasileira de Ensino de Biologia (SBEnBio), eleita para o biênio 2006-2008, atua como coordenadora do Núcleo de Estudos de Currículo (NEC/UFRJ) e do projeto de extensão universitária "Projeto Fundão Biologia". E-mail: mserra@ufri.br

\section{CARMEN TERESA GABRIEL}

Doutora em Educação pela Pontifícia Universidade Católica do Rio de Janeiro. Professora de Didática e de Prática de Ensino do curso de Licenciatura em História e do Programa de Pós-graduação em Educação da Universidade Federal do Rio de Janeiro. Pesquisadora do Núcleo de Estudos de Currículo (NEC/UFRJ), atua como coordenadora de Extensão do Centro de Filosofia de

Ciências Humanas (CFCH/UFRJ) e do projeto de extensão universitária

"Conexões de Saberes: diálogos entre a universidade e as comunidades populares".

E-mail: cartesa@alternex.com.br 